\title{
A Biofeedback Based Auto-Controlled Neurostimulator Design for Proper NCS Signal Acquisition and Measurement
}

\author{
C. Talukdar, A. Hazarika, A. Singh, N. Das, M. Bhuyan
}

\begin{abstract}
This paper presents the design of a biofeedback based auto-controlled neurostimulator for acquiring nerve response. Nerve conduction study (NCS) employs an electrical stimulator that generates a stimulus to be applied over the skin of an underlying nerve. Conventional neurostimulator uses manual control of voltage or current to generate the nerve responses. It is observed that the stimulation for supramaximal response varies with subjects due to different skin resistances of the subjects. Such measurement needs repeated trials which is time consuming, irritating to subjects and often suffers difficulties in real-time applications. This study proposes a portable neurostimulator based on the skin resistance as bio-feedback parameter to control the stimulus. A custom made NCS setup is developed for experimental recording of real-time nerve signals and identified the best compound muscle action potential signal for generating optimal stimulus i.e., supramaximal stimulus (SS) manually. Then, mathematical models are investigated using real-time data and models are implemented in a microcontroller $(\mu \mathrm{C})$ based stimulator. The $\mu C$ triggers a pulse train of specific duty cycle to a buck converter for producing the required optimal voltage which is used as a SS across the electrodes. Online experimental results with new subjects show that the proposed design is efficacious and adaptable with safety.
\end{abstract}

Keywords: Biofeedback, Neurostimulator, Skin resistance, supramaximal stimulation, Nerve conduction study (NCS)

\section{INTRODUCTION}

A neurostimulator used in a nerve conduction study (NCS) applies stimulating pulse voltage to the underlying nerve for proper excitation and recording of the compound muscle action potential (CMAP) for detection of various nerve disorders [1, 2]. This CMAP signal depends on the skin resistance of the subject which varies with subjects $[3,4]$. High resistance of the skin electrode interface reduces the current passing through the skin tissues resulting in ineffective nerve response [5-7]. Due to wide variation of skin resistance from subject to subject, a conventional stimulator requires repeated trials in order to find the optimal stimulating voltage, termed the supramaximal stimulus (SS), at which best NCS responses are observed. However, this is

Revised Manuscript Received on February 05, 2020.

* Correspondence Author

C. Talukdar, M.Sc. degree in Instrumentation from Gauhati University, Guwahati, Assam, India.

A. Hazarika, M.Sc. degree in Physics and the M Tech degree in Bioelectronics in 2009 and 2011 from Tezpur University, Tezpur,

A. Singh, B.E degree in Power Electronics and Instrumentation Engineering 2013 from Dibrugarh University, India

N. Das, B.E degree in Power Electronics and Instrumentation Engineering 2014 from Dibrugarh University, India

M. Bhuyan, Professor with the Department of Electronics and Communication Engineering, Tezpur University, Tezpur, India

(C) The Authors. Published by Blue Eyes Intelligence Engineering and Sciences Publication (BEIESP). This is an open access article under the CC BY-NC-ND license (http://creativecommons.org/licenses/by-nc-nd/4.0/) time consuming for doctors and irritating to the subjects. In that context, a stimulator design that can measure the skin resistance of a subject to find subject specific optimal stimulation could be an improvement. Recent studies reported various stimulator designs for various applications. In [1], a 64-channel neurostimulator was developed for deep brain stimulation and demonstrated the feasibility of the device in vivo using animal. Qian et al. [2] introduced a neurostimulator, however, this stimulator generates pulses of range $0-2.5 \mathrm{~V}$ for therapeutic application. Dorgan et al. [3] provided a theoretical human skin-impedance model for intelligent nerve activation with typically low frequency, high amplitudes and rectangular pulses to reduce pain. A wireless device [8] produced current controlled stimulation with frequency $0-60 \mathrm{~Hz}$ for peripheral nerves. Many similar work includes CMOS based neurostimulation [9], a plantable stimulator (PS) [10], wireless neural stimulation (WNS) [11], VLSI based stimulation for therapeutic applications [12] and a manual-controlled stimulator (MCS) [13]. The functional neural stimulator chip [10] aimed to minimize the value of off-blocking capacitor. It minimized the capacitance to picofarad range from microfarad range and it was integrated on a single silicon chip for fail-safe by using a high-frequency current switching technique. The blocking capacitor was used to limit the charge on the electrodes to ensure adequate safety. WNS provides constant current pulses of varying amplitude, duration, while MCS generates a unipolar rectangular pulse of duration $0.1 \mathrm{~ms}$ and varying amplitude (i.e., 10-60 V). However, no feedback technology was used to control the stimulus automatically. The stimulator was tested on the vagas nerve. The aforementioned neurostimulators are designed for application specific task; however, they did not adopt any intrinsic biofeedback parameter for controlling the stimulator. This could minimize unnecessary repeated trials avoiding nerve injury and wasted physician time. Therefore, biofeedback controlled nerve stimulators have been developed for therapeutic application. Zeng et al. [14] adopted a signal acquisition and a biofeedback system based on electrical muscle stimulation and surface EMG. It further fed signal features to classifier and finally controlled the stimulator based on results and levels of fatigue. Methods in

[15] and [16] are biofeedback based approaches, where the former addressed decision making system based on features of galvanic skin response and EMG signals and the latter explored on the use of EMG feature based electrical biofeedback stimulation. However, inherent characteristics and objectives of [15] and [16] are different from our design that would be presented herein. 
Precise and accurate measurement that includes signal recording, processing and analysis is a cornerstone of biomedical applications [17-20]. Many applications including neurorecording systems [21] and support systems $[22,23]$ focus on improvement of measurements and quality assessments. Besides microprocessor based systems, micro and nanotechnology have also gained attention in medical diagnosis [24].

These technologies require complex fabrication to enable optical, mechanical and electrical biosensor platforms with high sensitivity for medical applications.

As stated earlier, the quality of signal recording depends on skin-electrode interface resistance [25] and the applied stimulation [1-3, 8, 9]. The variations of skin-resistance alter the quality and quantitative values of NCS recordings [26]. Therefore proper stimulation using skin resistance of a subject as biofeedback, is essential for NCS. The core focus of this study is to design an auto-controlled biofeedback based stimulator utilizing measured skin resistance of subjects for NCS acquisition. The novelty of the design lies on using skin resistance as biofeedback. The article is summarized as follows:

1. Design of a conventional NCS setup with manual stimulator for multiple stimulations and acquisition of CMAP for experimentation. The NCS responses are compared with standard NCS record in terms of CMAP amplitude i.e., supramaximal response (SR). The stimulation corresponding to this SR is termed supramaximal stimulus.

2. A skin resistance biofeedback model was designed based on the measurement method of [27]. A theoretical model was established for finding the relation between a measured load voltage and skin resistance. Then a technique was developed for automatic generation of the SS depending on the skin resistance.

3. Finally, a $\mu C$ based auto-controlled stimulator was developed. In this setup, the developed models were implemented for automatic evaluation of the SS for new subjects. The design adopted a buck converter (BC) that generates online the stimulating voltage using a pulse train of a specific duty cycle (DC) that corresponds to the skin resistance of a subject.

The rest of the article is organized as follows. Section 2 describes the conventional NCS setup, Section 3 introduces the proposed auto-controlled stimulator and Section 4 provides the results and discussion. Section 5 concludes the article.

\section{DESIGN OF CONVENTIONAL NCS SETUP}

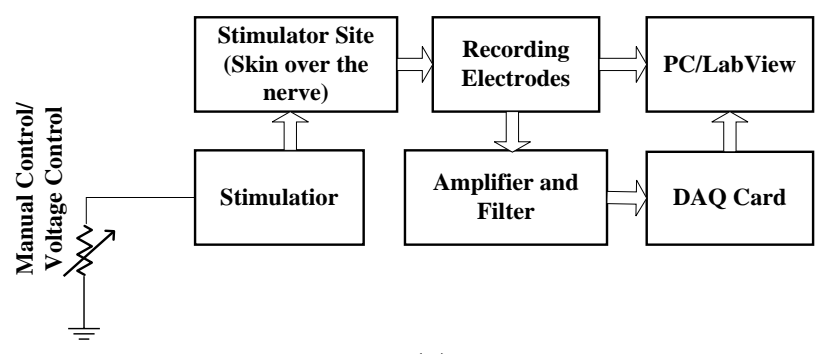

(a)

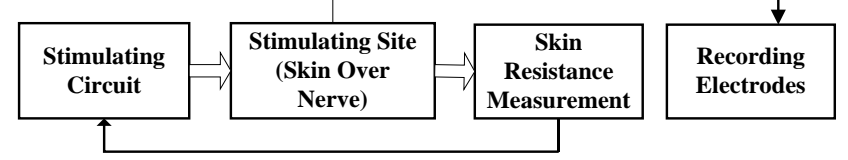

(b)

Fig. 1: a) Conventional NCS setup with manual stimulator, and b) proposed biofeedback based auto-controlled stimulation design.
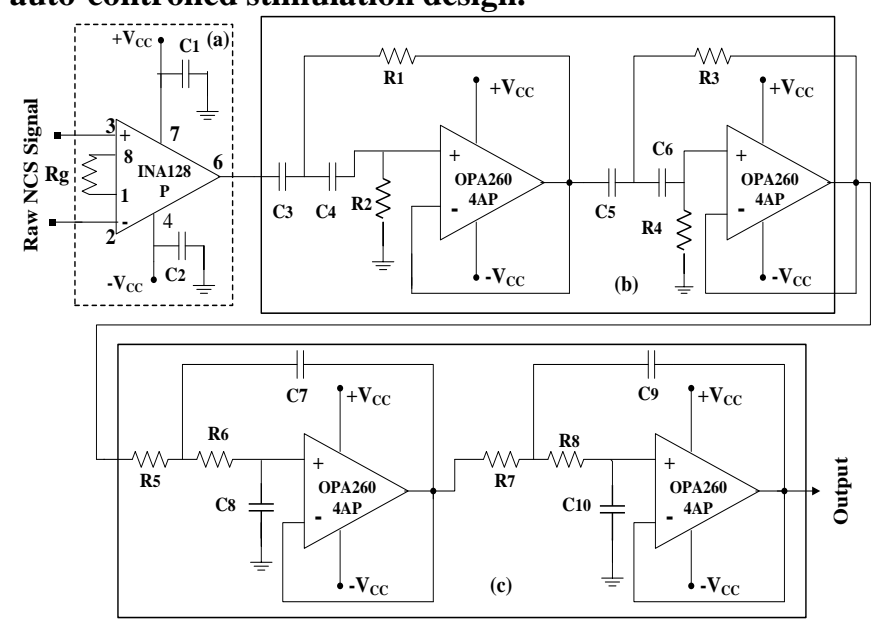

Fig. 2: Signal processing circuit. (a) instrumentation amplifier, and (b) and (c) are $2^{\text {nd }}$ order high pass and low pass filters respectively. $\left(V_{C C}=9 \mathrm{~V}\right)$.

Fig. 1 (a) shows the block diagram of the conventional NCS setup. It includes stimulator, recording electrodes (active, reference and ground), signal conditioning circuit and a DAQ system. In recording the signals, $\mathrm{Ag} / \mathrm{AgCl}$ surface electrodes [4] were placed over the skin of an underlying nerve and the nerve is stimulated by manual control. The electrode responses were acquired by a DAQ (NI6001) card. It is difficult to get high quality NCS signals, because of large noise amplitude coupled with wanted signal [28]. One of the sources of such noise is low frequency power line interference and its harmonics [29]. Movement of the patient causes loose electrode skin contact low frequency noises. The signal processing block consists of an instrumentation amplifier with gain of $300\left(A_{v}=1+50 \mathrm{k} / R_{g}, R_{g}\right.$ is the gain control resistance) in differential mode for better noise immunity [30, 31] and a filter to eliminate noise. To avoid low and high frequency noise that usually falls below $2 \mathrm{~Hz}$ and above $10 \mathrm{kHz}$ [32], a fourth order Butterworth band-pass filter using OPA2604AP is designed to give roll-off of \pm 12 $\mathrm{dB} /$ Octave at each stage [33].

We tested the SNR values of the two types of filters - single first order and two cascaded second order filter. The SNR values were found to be $49.3 \mathrm{~dB}$ and $71.2 \mathrm{~dB}$ respectively. Fig. 2 (b)-(c) shows the filter circuit. The filtered signal was detected and stored in PC through DAQ card.

\section{PROPOSED AUTO-CONTROLLED STIMULATOR}

This section focuses on design of an auto-controlled stimulator using skin resistance as biofeedback with the conceptual block diagram as shown in Fig. 1 (b).

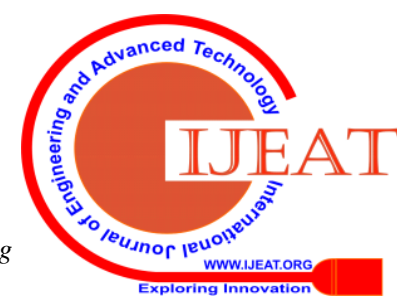


This section first outlines the theoretical principle of using skin resistance as biofeedback and then focuses on measurement of skin resistance of subjects and its implementation.

\section{A. Skin resistance as Biofeedback}

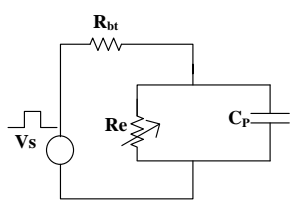

(a)

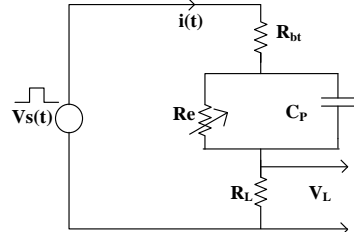

(b)
Fig. 3: Skin-electrode circuit (a) interface model [27], and (b) measurement circuit

Skin is composed of two layers - epidermis (outer) and dermis (inner). The total skin thickness varies from $0.5 \mathrm{~mm}$ at the eylid to about $4 \mathrm{~mm}$ at the foot sole [27]. Tissues in the dermis contain more ions that provide low resistance; however, the epidermis layer provides maximum resistance to ionized-species at the skin electrode interface. During stimulation, the resistance often get changed due to structural changes of skin, either instantaneous change [34] or progressive change [35]. Instantaneous change causes increase in membrane permeability to ions to the electric field [36]. Fig. 3 (a) shows the skin-electrode interface model [27] based on which a measurement circuit was designed. In Fig. 3 (a), $R_{b t}$ indicates series combination of bulk of electrolyte resistance. The capacitor $C_{p}$ is referred to as appendages of the skin and $R_{e}$ is leakage resistance due to the lipid-corneocyte matrix for electroporation effect that varies with subjects. This is caused by to activity of sweat glands, presence of other appendageal pathways, thickness and composition of stratum corneum and it also depends on age and sex [37], fat percentage and fat-free mass of body [38]. When the stimulator voltage $\left(V_{S}\right)$ is applied, first $C_{p}$ charges which then discharges through $R_{e}$ and $R_{b t}$. The net current is given by:

$$
i=\frac{V_{S}}{R_{b t}+R_{e}}=\frac{V_{S}}{R_{S}}
$$

where, $R_{S}=R_{b t}+R_{e}$ is the total skin resistance. Based on Fig. 3(a), the proposed measurement circuit is shown in Fig. 3 (b) which includes a load resistance $R_{L}$ across which the load voltage $\left(V_{L}\right)$ is measured. The resistances of the circuitry are linearly dependent upon temperature ( $R=R_{0}(1+\alpha d T)$ ) being temperature coefficient. So, in order to avoid additional variations in measuring the skin resistance, the experiment was conducted at constant room temperature $\left(25^{0} \mathrm{C}\right)$.

\section{B. Skin-Resistance Measurement}

In order to measure total skin resistance $\left(R_{S}\right)$, a stimulating voltage $V_{S}(t)$ was applied to produce a voltage $V_{L}(t)$ across $R_{L}$. For monophasic, i.e., single phase voltage, $R_{S}$ is given by:

$$
R_{S}=R_{L}\left(\frac{V_{S}(t)}{V_{L}(t)}-1\right)_{t=t_{1}}
$$

The time stamp $t_{1}$ is defined as the time at which the capacitor $C_{P}$ gets fully charged so that the load voltage $V_{L}$ also reaches a stable value. In the proposed framework $V_{S}$ is mapped with the corresponding measured $V_{L}$ which is fed to the stimulator circuit as biofeedback.

\section{Data generation and theoretical modeling}

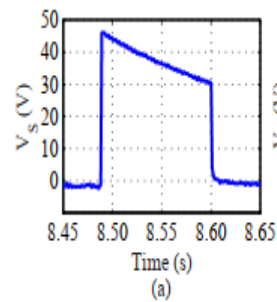

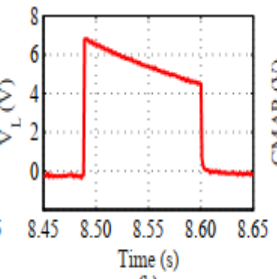

(b)

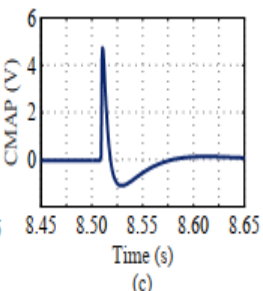

Fig. 4: Typical signals with conventional setup (a) applied stimulating voltage (46 V), (b) acquired load voltage and (c) recorded CMAP.

The experiment was conducted over 16 subjects ( 9 males, age range: 20-35 years, height: 165.1-180.34 cm, BMI: 17.4-33.8 $\mathrm{kg} / \mathrm{m}^{2}$ and 7 females, age range: 20-30 years, height: 160-170.2 cm, BMI: 16.4-25.9 kg/m² with different body weights under the supervision of a neurophysiologist at Guwahati Neurological Research Centre (GNRC) hospital, Assam, India. Subjects were asked to lay on bed for at least 5 min and then, stimulating and recording sites were cleaned with alcohol and paste conducting gel placed over the skin. The measurement was conducted for 45 min (approx.) for each subject using commercially available surface electrodes. The stimulating electrode was $5 \mathrm{~mm}$ diameter with inter-electrode gap $1.5 \mathrm{~cm}$ and the recording electrode was 10 mm diameter (Medicaid Neuroperfect). Ag/AgCl electrode was typically used for stable electrode polarization [6] and the impedance of electrode should be less than $5-10 \mathrm{k} \Omega$ for acceptable recording [39]. In this experiment, the measured impedance of the electrode used was found to be $\sim 2.7 \mathrm{k} \Omega$. For minimizing the impedance during the measurement, the electrodes as well as skin-electrode contacts were cleaned and conducting gel was used over the electrodes as well as on the skin. The active and reference electrodes were placed over the underlying locations and the ground electrode was placed on the wrist between stimulating and recording electrodes to avoid electrical shock and unwanted noise. The left upper limb median nerve under

the abductor pollicis brevis muscle was taken for stimulation and CMAP signals were recorded.For acquiring data using the custom NCS setup, initially, low voltage was applied which was then gradually increased to achieve the supramaximal response (i.e., best CMAP). To estimate the resistances using Eq. (2), $V_{S}(t)$ and $V_{L}(t)$ were acquired. This was done in order to derive model characteristics between $R_{S}$ and supramaximal stimulating voltage ( $V_{S M}$ ), at a stimulating voltage where best CMAP response was obtained. For modeling, stimulating voltages were applied and corresponding load voltages were obtained. 
Signals were acquired using DAQ with sampling frequency of $1 \mathrm{kHz}$ and a set of typical signals is shown in Fig. 4. It is observed that the supramaximal CMAP is obtained at different triggering voltages for male and female subjects of different body weights. Taking these as basis, we propose two sets of models using dependable parameters for male and female subjects as follows:

$$
\begin{aligned}
& E\left(V_{L, S M}\right)_{m}=f\left(V_{L}, \infty\right)_{m} \ldots \\
& E\left(V_{S M}\right)_{m}=f\left(V_{L, S M}, \beta\right)_{m} \\
& E\left(V_{L, S M}\right)_{f}=f\left(V_{L}, \gamma\right)_{f} \ldots
\end{aligned}
$$

$$
E\left(V_{S M}\right)_{f}=f\left(V_{L, S M}, \varphi\right)_{f}
$$

We set different parameter constants, $\infty=\{a, b, \ldots . .$.$\} ;$ $\beta=\{c, d, \ldots \ldots .$.$\} for male subject (m)$ and $\gamma=\{p, q \ldots \ldots .$.$\} ;$ $\varphi=\{r, s . . . .$.$\} for female subject (f)$ according to our formulation.

\section{D. $\mu C$ based stimulator design}

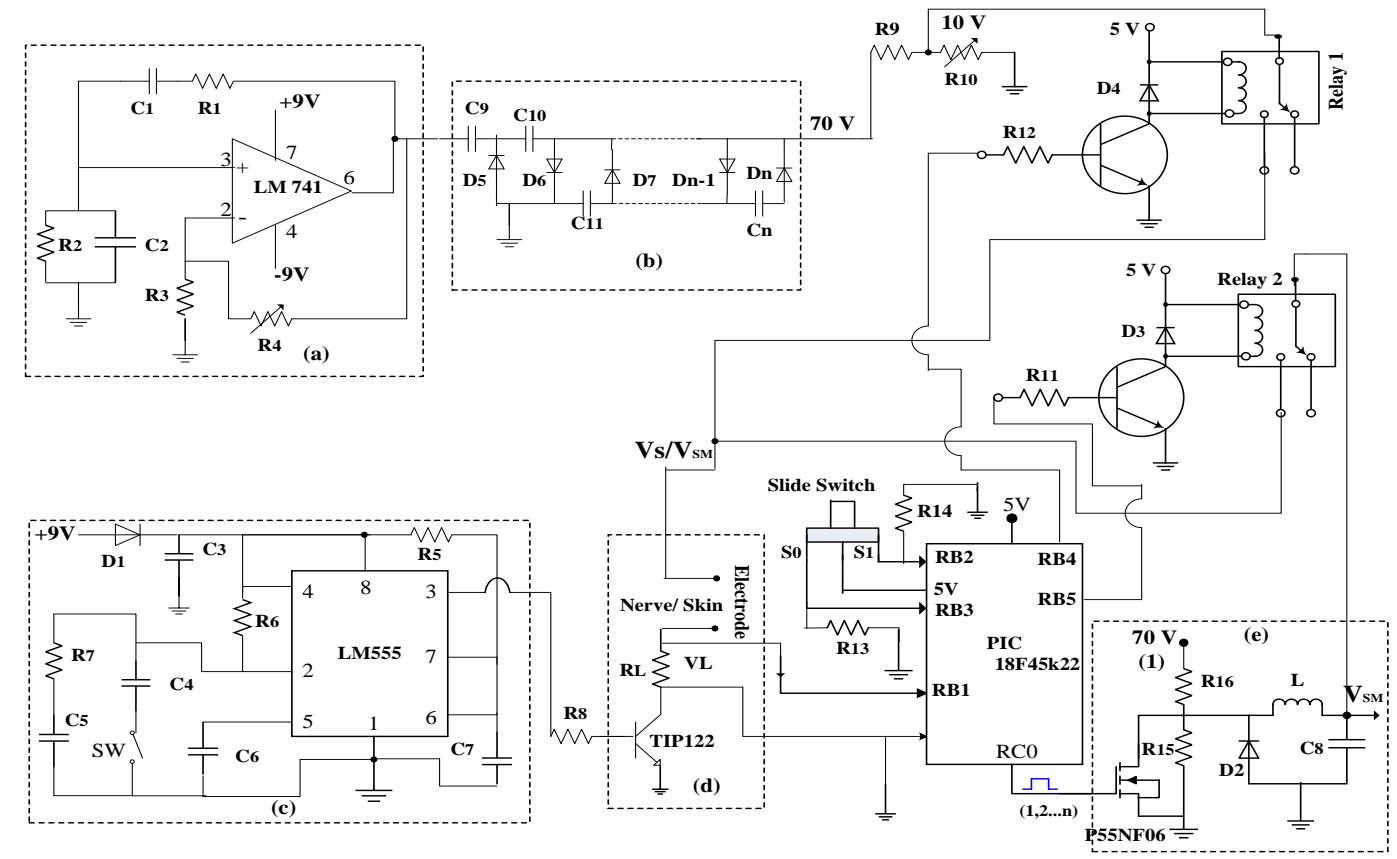

Fig. 5: $\mu C$-based auto-controlled stimulator circuit. (a) oscillator, (b) 8-stage voltage multiplier (VM), (c) timer circuit (d) electrode system and (e) BC. The oscillator circuit is powered by two $9 \mathrm{~V}$ lithium-ion batteries. It was designed to generate sustainable and stabilized sinusoidal oscillation and its oscillation frequency was $7.23 \mathrm{kHz}$. The output of the oscillator was fed to the VM that generates up to $70 \mathrm{~V}$. The timer circuit was designed to generate a pulse duration of $110 \mathrm{~ms}$ [6]. Voltage divider unit $\left(R_{9}\right.$ and $\left.R_{10}\right)$ was adjusted to produce $10 \mathrm{~V}$ from $70 \mathrm{~V}$. When $\mathrm{SW}$ is $\mathrm{ON}$, the $V_{L}$ is obtained across $R_{L}$, which is connected to $\mu C$ via port RB1. The pins S1 and S0 of the sliding switch were used to select female and male subject respectively, which were connected to the ports RB2 and RB3. Relays RLY1 and RLY2 were used to apply $V_{S}$ of $10 \mathrm{~V}$ and $V_{S M}$ respectively through $\mathbf{R B} 4$ and $\mathrm{RB} 5$. Initially, $\mathrm{RB} 2-\mathrm{RB} 5$ were low while $\mu C$ power was on. When RB4 is high, RLY1 is $\mathrm{ON}$ and initial voltage $V_{S}=10 \mathrm{~V}$ is applied to the subject via electrode by pressing the push button switch, SW for first time. This produces a pulse train in RCO of a specific duty cycle corresponding to the $V_{S M}$ calculated by $\boldsymbol{\mu C}$ so as to apply to the MOSFET of the BC in order to obtain $V_{S M}$ at output. Now pin RB5 goes to high state so that RLY2 is on and simultaneously pin RB4 goes low state so as to make RLY1 OFF. This $V_{S M}$ appeares across the electrode via RLY2 for final stimulation as soon as switch SW is pressed for the second time.

Fig. 5 shows the developed $\mu C$-based auto-controlled neurostimulator which is composed of five modules (a)-(e). A set of mathematical models according to the formulation described in section 3.3, were analyzed by employing real-time data and the statistically optimal models were implemented in a $\mu C$ for automatic generation of $V_{S M}$.

For a given $V_{S}(10 \mathrm{~V})$, the programmed $\mu C$ will determine $V_{S M}$ using $V_{L}$ for a particular subject. This $V_{S M}$ triggers a particular pulse train to be applied to the MOSFET of a BC in order to generate the supramaximal stimulus voltage. Prior to this, relation between DC of pulse trains and output voltage of BC were calibrated, and implemented in $\mu C$ for producing the estimated $V_{S M}$. The SS appears across the electrode for final stimulation via relay 2 . The $\mu C$ generates a pulse train with amplitude of $0-5 \mathrm{~V}$ which is further adjusted to $0-1 \mathrm{~V}$ with a frequency of $10 \mathrm{kHz}$ to ensure linear voltage variations of $\mathrm{BC}$ with the $\mathrm{DC}$ for finding the desired $V_{S M}$ at the BC output. 
Therefore, we can relate the output of the BC $\left(V_{B C}\right)$ i.e., $V_{S M}$ proportionately with the DC of the pulse train.

$$
V_{S M}=K \times D C
$$

where $K$ is a constant. The design employs an 8-bit PIC $\mu C$ which has a RISC CPU and 10-bit ADC, and the program was coded in mikro $\mathrm{C}$ pro. The $\mu C$ coded program size is of 2 $\mathrm{kB}$ and it uses $21 \mid \%$ of ROM. The sampling frequency is 25 $\mathrm{kHz}$. The values of $V_{S}$ and $V_{S M}$ are displayed in $20 \times 4$ alphanumeric LCD.

\section{RESULTS AND DISCUSSION}

Table 1: Skin resistance measurements for wide applied voltages $\left(V_{S}\right)$ over male subjects (weight range: $45-110 \mathrm{~kg}$, mean: 74.2 \pm 20.32 kg) (Part-I)

\begin{tabular}{|c|c|c|c|c|c|c|c|c|c|}
\hline \multicolumn{10}{|c|}{ Skin-resistance $R_{S}(\mathrm{k} \Omega) \pm \mathrm{SD}$} \\
\hline$V_{S}(\mathrm{~V})$ & $\begin{array}{l}\text { [For S1] } \\
49 \mathrm{~kg}\end{array}$ & $\begin{array}{l}\text { [For S2] } \\
53 \mathrm{~kg}\end{array}$ & $\begin{array}{l}\text { [For S3] } \\
57 \mathrm{~kg}\end{array}$ & $\begin{array}{l}\text { [For S4] } \\
65 \mathrm{~kg}\end{array}$ & $\begin{array}{l}\text { [For S5] } \\
72 \mathrm{~kg}]\end{array}$ & $\begin{array}{l}\text { [For S6] } \\
80 \mathrm{~kg}\end{array}$ & $\begin{array}{l}\text { [For S7] } \\
87 \mathrm{~kg}\end{array}$ & $\begin{array}{l}\text { [For S8] } \\
93 \mathrm{~kg}\end{array}$ & $\begin{array}{l}\text { [For S9] } \\
110 \mathrm{~kg}\end{array}$ \\
\hline 10 & $\begin{array}{l}8.074 \\
\pm 2.10 \\
\end{array}$ & $\begin{array}{l}9.611 \\
\pm 2.25 \\
\end{array}$ & $\begin{array}{l}10.570 \\
\pm 2.55 \\
\end{array}$ & $\begin{array}{l}12.473 \\
\pm 2.66 \\
\end{array}$ & $\begin{array}{l}12.94 \\
\pm 2.92 \\
\end{array}$ & $\begin{array}{l}14.634 \\
\pm 3.21 \\
\end{array}$ & $\begin{array}{l}16.780 \\
\pm 3.20 \\
\end{array}$ & $\begin{array}{l}19.316 \\
\pm 3.23 \\
\end{array}$ & $\begin{array}{l}24.920 \\
\pm 3.25 \\
\end{array}$ \\
\hline 15 & $\begin{array}{l}6.804 \\
\pm 1.98 \\
\end{array}$ & $\begin{array}{l}8.282 \\
\pm 2.12 \\
\end{array}$ & $\begin{array}{l}9.0040 \\
\pm 2.43 \\
\end{array}$ & $\begin{array}{l}10.811 \\
\pm 2.48 \\
\end{array}$ & $\begin{array}{l}11.23 \\
\pm 2.70 \\
\end{array}$ & $\begin{array}{l}12.357 \\
\pm 3.05 \\
\end{array}$ & $\begin{array}{l}14.861 \\
\pm 3.09 \\
\end{array}$ & $\begin{array}{l}15.966 \\
\pm 3.15 \\
\end{array}$ & $\begin{array}{l}19.618 \\
\pm 3.20 \\
\end{array}$ \\
\hline 20 & $\begin{array}{l}6.312 \\
\pm 1.83 \\
\end{array}$ & $\begin{array}{l}7.274 \\
\pm 2.05 \\
\end{array}$ & $\begin{array}{l}8.2890 \\
\pm 2.24 \\
\end{array}$ & $\begin{array}{l}9.111 \\
\pm 2.35 \\
\end{array}$ & $\begin{array}{r}10.63 \\
\pm 2.65 \\
\end{array}$ & $\begin{array}{l}11.150 \\
\pm 2.89 \\
\end{array}$ & $\begin{array}{l}12.431 \\
\pm 2.92 \\
\end{array}$ & $\begin{array}{l}13.347 \\
\pm 2.97 \\
\end{array}$ & $\begin{array}{l}16.490 \\
\pm 3.01 \\
\end{array}$ \\
\hline 25 & $\begin{array}{l}6.014 \\
\pm 1.72 \\
\end{array}$ & $\begin{array}{l}6.880 \\
\pm 1.94 \\
\end{array}$ & $\begin{array}{l}7.2780 \\
\pm 2.13 \\
\end{array}$ & $\begin{array}{l}7.796 \\
\pm 2.24 \\
\end{array}$ & $\begin{array}{r}9.730 \\
\pm 2.51 \\
\end{array}$ & $\begin{array}{l}10.215 \\
\pm 2.72 \\
\end{array}$ & $\begin{array}{l}11.224 \\
\pm 2.79 \\
\end{array}$ & $\begin{array}{l}12.220 \\
\pm 2.84 \\
\end{array}$ & $\begin{array}{l}14.060 \\
\pm 2.93 \\
\end{array}$ \\
\hline 30 & $\begin{array}{l}5.605 \\
\pm 1.59 \\
\end{array}$ & $\begin{array}{l}6.062 \\
\pm 1.81 \\
\end{array}$ & $\begin{array}{l}6.8570 \\
\pm 2.02 \\
\end{array}$ & $\begin{array}{l}7.045 \\
\pm 2.11 \\
\end{array}$ & $\begin{array}{r}7.520 \\
\pm 2.39 \\
\end{array}$ & $\begin{array}{l}9.200 \\
\pm 2.61 \\
\end{array}$ & $\begin{array}{l}10.025 \\
\pm 2.65 \\
\end{array}$ & $\begin{array}{l}11.024 \\
\pm 2.71 \\
\end{array}$ & $\begin{array}{l}12.800 \\
\pm 2.78 \\
\end{array}$ \\
\hline 35 & $\begin{array}{l}5.159 \\
\pm 1.50 \\
\end{array}$ & $\begin{array}{l}5.321 \\
\pm 1.68 \\
\end{array}$ & $\begin{array}{l}6.2990 \\
\pm 1.77 \\
\end{array}$ & $\begin{array}{l}6.641 \\
\pm 1.94 \\
\end{array}$ & $\begin{array}{r}7.239 \\
\pm 2.26 \\
\end{array}$ & $\begin{array}{l}8.600 \\
\pm 2.48 \\
\end{array}$ & $\begin{array}{l}8.929 \\
\pm 2.57 \\
\end{array}$ & $\begin{array}{l}9.297 \\
\pm 2.62 \\
\end{array}$ & $\begin{array}{l}10.164 \\
\pm 2.69 \\
\end{array}$ \\
\hline 40 & $\begin{array}{r}4.841 \\
\pm 1.36 \\
\end{array}$ & $\begin{array}{l}5.015 \\
\pm 1.55 \\
\end{array}$ & $\begin{array}{l}5.7200 \\
\pm 1.59 \\
\end{array}$ & $\begin{array}{l}6.092 \\
\pm 1.78 \\
\end{array}$ & $\begin{array}{r}6.765 \\
\pm 2.05 \\
\end{array}$ & $\begin{array}{r}7.840 \\
\pm 2.29 \\
\end{array}$ & $\begin{array}{l}8.095 \\
\pm 2.32 \\
\end{array}$ & $\begin{array}{l}8.498 \\
\pm 2.39 \\
\end{array}$ & $\begin{array}{l}9.175 \\
\pm 2.44 \\
\end{array}$ \\
\hline 45 & $\begin{array}{r}4.365 \\
\pm 1.23 \\
\end{array}$ & $\begin{array}{l}4.576 \\
\pm 1.41 \\
\end{array}$ & $\begin{array}{l}5.1110 \\
\pm 1.43 \\
\end{array}$ & $\begin{array}{r}5.806 \\
\pm 1.65 \\
\end{array}$ & $\begin{array}{r}5.997 \\
\pm 1.83 \\
\end{array}$ & $\begin{array}{r}6.270 \\
\pm 1.98 \\
\end{array}$ & $\begin{array}{r}6.486 \\
\pm 2.11 \\
\end{array}$ & $\begin{array}{r}6.813 \\
\pm 2.23 \\
\end{array}$ & $\begin{array}{r}7.685 \\
\pm 2.29 \\
\end{array}$ \\
\hline 50 & $\begin{array}{r}3.782 \\
\pm 1.04 \\
\end{array}$ & $\begin{array}{r}4.086 \\
\pm 1.19 \\
\end{array}$ & $\begin{array}{l}4.6820 \\
\pm 1.24 \\
\end{array}$ & $\begin{array}{r}5.550 \\
\pm 1.46 \\
\end{array}$ & $\begin{array}{r}5.619 \\
\pm 1.58 \\
\end{array}$ & $\begin{array}{r}5.940 \\
\pm 1.77 \\
\end{array}$ & $\begin{array}{r}6.155 \\
\pm 1.91 \\
\end{array}$ & $\begin{array}{r}6.354 \\
\pm 2.01 \\
\end{array}$ & $\begin{array}{r}6.665 \\
\pm 2.14 \\
\end{array}$ \\
\hline 55 & $\begin{array}{l}3.096 \\
\pm 0.89 \\
\end{array}$ & $\begin{array}{l}3.625 \\
\pm 1.05 \\
\end{array}$ & $\begin{array}{l}3.8970 \\
\pm 1.12 \\
\end{array}$ & $\begin{array}{r}4.809 \\
\pm 1.28 \\
\end{array}$ & $\begin{array}{r}4.826 \\
\pm 1.33 \\
\end{array}$ & $\begin{array}{r}5.029 \\
\pm 1.71 \\
\end{array}$ & $\begin{array}{r}5.259 \\
\pm 1.76 \\
\end{array}$ & $\begin{array}{l}5.429 \\
\pm 1.80 \\
\end{array}$ & $\begin{array}{r}6.046 \\
\pm 1.83 \\
\end{array}$ \\
\hline
\end{tabular}

Table 2: Skin resistance measurements for wide applied voltages over female subjects (weight range: $40-75 \mathrm{~kg}$, mean: $57.7 \pm 12.07$ kg) (Part-II)

\begin{tabular}{|c|c|c|c|c|c|c|c|}
\hline \multicolumn{8}{|c|}{ Skin-resistance $R_{S}(\mathrm{k} \Omega) \pm \mathrm{SD}$} \\
\hline$V_{S}(\mathrm{~V})$ & $\begin{array}{l}\text { [For S1] } \\
42 \mathrm{~kg}\end{array}$ & $\begin{array}{l}\text { [For S2] } \\
46 \mathrm{~kg}\end{array}$ & $\begin{array}{l}\text { [For S3] } \\
51 \mathrm{~kg}\end{array}$ & $\begin{array}{l}\text { [For S4] } \\
58 \mathrm{~kg}\end{array}$ & $\begin{array}{l}\text { [For S5] } \\
64 \mathrm{~kg}]\end{array}$ & $\begin{array}{l}\text { [For S6] } \\
68 \mathrm{~kg}\end{array}$ & $\begin{array}{l}\text { [For S7] } \\
75 \mathrm{~kg}\end{array}$ \\
\hline 10 & $4.945 \pm 1.89$ & $5.459 \pm 1.89$ & $5.988 \pm 1.72$ & $6.757 \pm 1.60$ & $7.460 \pm 1.46$ & $8.363 \pm 1.34$ & $10.15 \pm 1.25$ \\
\hline 15 & $4.512 \pm 1.93$ & $5.172 \pm 1.75$ & $5.678 \pm 1.58$ & $5.996 \pm 1.52$ & $6.739 \pm 1.31$ & $7.542 \pm 1.27$ & $8.469 \pm 1.18$ \\
\hline 20 & $4.006 \pm 1.84$ & $4.197 \pm 1.62$ & $4.768 \pm 1.43$ & $5.644 \pm 1.38$ & $6.142 \pm 1.23$ & $6.448 \pm 1.15$ & $7.658 \pm 1.06$ \\
\hline 25 & $3.454 \pm 1.71$ & $3.616 \pm 1.53$ & $3.744 \pm 1.32$ & $5.044 \pm 1.29$ & $5.522 \pm 1.17$ & $6.058 \pm 1.07$ & $7.033 \pm 0.97$ \\
\hline 30 & $2.977 \pm 1.59$ & $3.354 \pm 1.44$ & $3.430 \pm 1.26$ & $4.626 \pm 1.18$ & $5.082 \pm 1.11$ & $5.458 \pm 0.96$ & $6.610 \pm 0.86$ \\
\hline 35 & $2.705 \pm 1.48$ & $2.979 \pm 1.31$ & $3.167 \pm 1.12$ & $4.112 \pm 1.07$ & $4.263 \pm 1.04$ & $4.916 \pm 0.88$ & $5.789 \pm 0.79$ \\
\hline 40 & $2.337 \pm 1.39$ & $2.809 \pm 1.23$ & $3.002 \pm 1.08$ & $3.721 \pm 0.95$ & $3.899 \pm 0.92$ & $4.361 \pm 0.79$ & $5.463 \pm 0.71$ \\
\hline 45 & $2.030 \pm 1.26$ & $2.529 \pm 1.16$ & $2.584 \pm 0.99$ & $3.524 \pm 0.89$ & $3.502 \pm 0.78$ & $3.869 \pm 0.73$ & $4.664 \pm 0.65$ \\
\hline
\end{tabular}

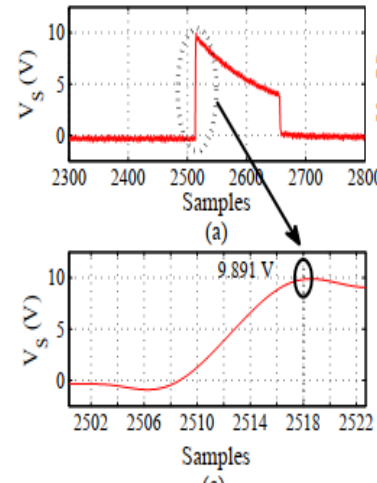

(c)

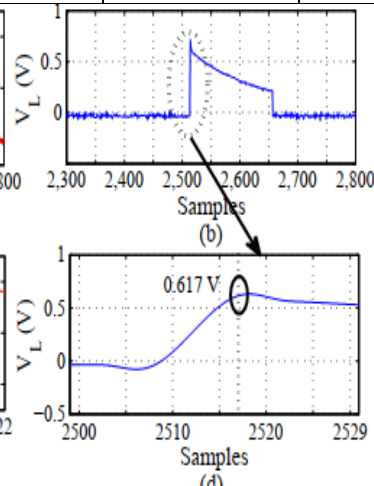

(d)
Fig. 6: Measured signals (a) applied stimulating voltage ( $\left.V_{S}=10 \mathrm{~V}\right)$ (b) load voltage $\left(V_{L}\right)$.

The zoomed versions of rising time of $V_{S}$ and $V_{L}$ of (a) and (b) at $t=t_{1}$ are shown in (c) and (d) respectively. A monophasic rectangular stimulator pulse with a time constant $<1 \mathrm{~ms}$ is used in the conventional NCS. The estimation of $R_{S}$ requires rising windows of both applied stimulating voltage $V_{S}$ and measured load voltage $V_{L}$ as shown in Fig.
6. Using Eq. (2) for a male subject for a voltage level at $t_{1}$ (at $99 \%$ peak levels) $R_{S}$ as $15.03 \mathrm{k} \Omega$ for $R_{L}=1 \mathrm{k} \Omega$ which agrees with the prior findings [27]. Another method [40] measured the resistance over the skin coated with gel and found resistance characteristics at applied frequency $1 \mathrm{~Hz}-1$ $\mathrm{MHz}$ that indicates resistance $\sim 100 \Omega-1 \mathrm{M} \Omega$. Specifically, at $10 \mathrm{~Hz}$ the resistance varies $\sim 10 \mathrm{k} \Omega-1 \mathrm{M} \Omega$. Our experimental results over a wide range of subjects (male and female participants) show that $R_{S}$ is in the range $\sim 2-25 \mathrm{k} \Omega$ which shows good agreement with previous studies.

Tables 1-2 show the variation of $R_{S}$ with $V_{L}$ for various subjects (male and female participants). Results are presented in terms of mean resistance with standard deviation as an error over five repeated measures at specific applied voltage for a given subject. The applied voltage ranges for male and female participants were kept at different levels by observing the optimal CMAP responses. A statistical test for optimal choice of voltage was also carried out which is statistically significant with $\mathrm{p}<0.005$. 
It is seen that the resistances are higher for subjects with higher body weight in both male and female subjects. However, the resistances for female subjects are smaller than that of male subjects for same weight and applied voltage. With increase in $V_{S}$, the resistance gradually decreases irrespective of gender as discussed in section 3.1. Therefore skin resistance profiles are different for male and female participants for the same range of applied voltage. The resistance profile for a given subject was found high initially and then decreased non-linearly with increase of applied stimulating voltage.

\section{B. Modeling of supramaximal stimulation (MoSS)}

MoSS requires measures of $V_{L}$ and $R_{S}$ for various applied voltages $\left(V_{S}\right)$. This experiment was carried out for an applied voltage range of $10-55 \mathrm{~V}$ to achieve SS. However, measurement in case of female subjects was kept in the range of 10-45 V since for female subjects SS was achieved at a lower level of applied voltage as compared to male subjects. Fig. 7 shows the variation of $V_{L}$ with $V_{S}$ in steps of $5 \mathrm{~V}$ for male and female subjects. During measurement optimum load voltages ( $\left.V_{L, S M}\right)$ for each subject are noted down manually by observing signals in the DAQ. The $V_{L, S M} \mathrm{~s}$ are marked with A1,..,F1 for females and A2,..,I2 for males. The markers represent $V_{S M}$ along $V_{S}$-axis and $V_{L, S M}$ along $V_{L}$-axis. For instance, C2 $(42,6.4)$ indicate $V_{S M}$ at $42 \mathrm{~V}$ and $V_{L, S M}$ at $6.4 \mathrm{~V}$ as shown in Fig. 7 (b). It is seen that $V_{L}$ with $V_{L, S M}$ and $V_{L, S M}$ with $V_{S M}$ can be mapped for finding statistical model. This framework opens up a methodology to estimate the SS for a subject.

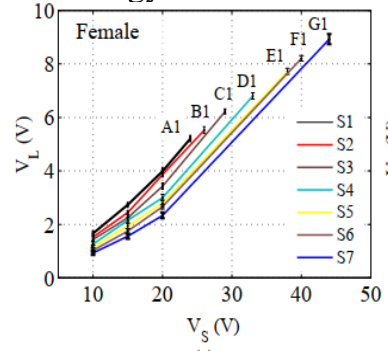

(a)

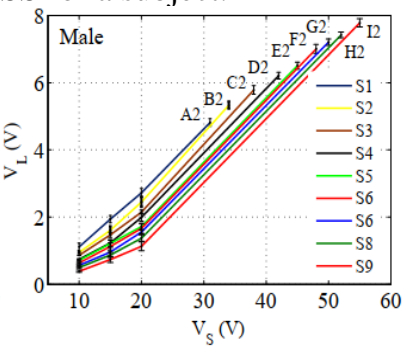

(b)
Fig.7: Measured load voltages $V_{L}$ for different applied voltages $V_{S}$ • (a) female subjects S1-S7 and (b) male subjects S1-S9. For female subjects $V_{L, S M}$ were obtained at specific applied voltages, termed as $V_{S M}$ (i.e., A1-G1) in the range of 20-45 $\mathrm{V}$ and for male $V_{L, S M}$ were obtained at various $V_{S M}$ (i.e. A2-I2) in the range of 30-60

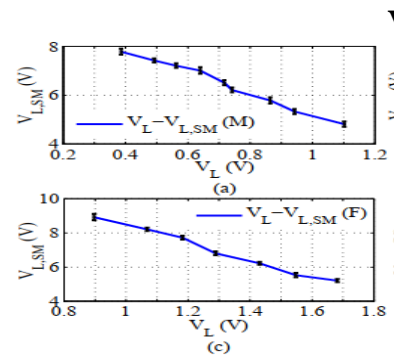
V.
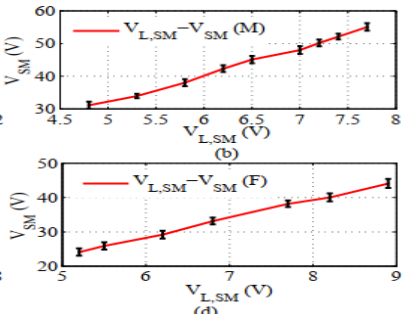

Fig. 8: Model characteristics of various subjects at $V_{S}=15$ V. (a) and (b) are for male, and (c) and (d) are for female.
Table 3: Regression analysis with $R^{2}$ for $V_{L, S M}-V_{L}$ and

\begin{tabular}{|c|l|l|l|}
\multicolumn{5}{|c}{$V_{S M}-V_{L, S M}$} \\
\hline Subject & Mathematical models & Model parameters & $R^{2}$ \\
\hline \multirow{5}{*}{ Male } & Eq.(10) $\left[V_{S}=10 \mathrm{~V}\right]$ & $\mathrm{a}=-4.332, \mathrm{~b}=9.537$ & $\mathbf{0 . 9 8 6 1}$ \\
\cline { 2 - 4 } & Eq.(10) $\left[V_{S}=15 \mathrm{~V}\right]$ & $\mathrm{a}=-2.576, \mathrm{~b}=9.634$ & 0.9826 \\
\cline { 2 - 4 } & Eq.(10) $\left[V_{S}=20 \mathrm{~V}\right]$ & $\mathrm{a}=-1.918, \mathrm{~b}=9.987$ & 0.9791 \\
\cline { 2 - 4 } & $\begin{array}{l}\text { Eq.(11) }\left[V_{S}=V_{S M}\right. \\
\text { V] }\end{array}$ & $\mathrm{c}=8.041, \mathrm{~d}=-8.062$ & $\mathbf{0 . 9 9 5 9}$ \\
\hline \multirow{5}{*}{ Female } & Eq.(12) $\left[V_{S}=10 \mathrm{~V}\right]$ & $\mathrm{p}=-5.032, \mathrm{q}=13.47$ & $\mathbf{0 . 9 8 4 1}$ \\
\cline { 2 - 4 } & Eq.(12) $\left[V_{S}=15 \mathrm{~V}\right]$ & $\mathrm{p}=-3.493, \mathrm{q}=14.32$ & 0.962 \\
\cline { 2 - 4 } & Eq.(12) $\left[V_{S}=20 \mathrm{~V}\right]$ & $\mathrm{p}=-2.194, \mathrm{q}=13.86$ & 0.9698 \\
\cline { 2 - 4 } & $\begin{array}{l}\text { Eq.(13) }\left[V_{S}=V_{S M}\right. \\
\text { V] }\end{array}$ & $\mathrm{r}=5.667, \mathrm{~s}=-5.549$ & $\mathbf{0 . 9 9 8 3}$ \\
\hline
\end{tabular}

Table 4: Operation of the $\mu C$ based auto-controlled neurostimulator

\section{Step I: Model implementation (Offline measurement using LabView)}

i. Apply $V_{S}$ for study subjects (S)

ii. Find $V_{L} \mathrm{~s} \forall \mathrm{s}$

iii. Find model equations for $V_{S M}$ and $V_{L, S M}$ using MATLAB

iv. Find optimum model using $R^{2}$ and initial triggering voltage

v. Embed program in $\mu C$ for evaluation of $V_{S M}$

Step II: Buck converter (Offline measurement)

i. Find relation between input DC and output voltage of BC ( $\left.V_{B C}\right)$

ii. Find DC for $V_{S M}$ and embed program in $\mu C$

iii. Embed the program to trigger a pulse train with specific DC to generate

corresponding $V_{S M}$

Step III: Evaluation of $V_{S M}$ for Online measurement

i. Select subject (male/female) for recording

ii. Apply optimal trigger voltage to the nerve by setting the output voltage of voltage multiplier

iii. Measure $V_{L}$

iv. Calculate $V_{L, S M}$ and $V_{S M}$ for model equations

v. Calculate DC using Eq.(9)

vi. Output the pulse train with the calculated DC.

The variation of $V_{L}$ and $V_{L, S M}$ with $V_{S}$ and $V_{S M}$ respectively for both male and female subjects (Fig. 8) was used to fit to our model equations. In order to establish the mathematical relationships between the variables, a number of models were investigated in MATLAB. Subsequently, two sets of models for both male and female subjects were investigated based on a simple linear equation connecting two measurement points. These equations are simple and have less computational complexity for ease of implementation.

$$
\begin{gathered}
V_{L, S M, m}=a V_{L, m}+b \ldots \\
V_{S M, m}=c V_{L, S M, m}+d . \\
V_{L, S M, f}=p V_{L, f}+q \ldots \\
V_{S M, f}=r V_{L, S M, f}+S \ldots
\end{gathered}
$$


where $a, c, p, r$ are model gains and $b, d, q, s$ are model offsets. The subscripts $m$ and $f$ indicate male and female respectively. Table 3 reports the best fits in terms of $R^{2}$ evaluated for $V_{S}=10 \mathrm{~V}, 15 \mathrm{~V}$ and $20 \mathrm{~V}$. The best fit models for $V_{L, S M}-V_{L}$ and $V_{S M}-V_{L, S M}$ were found at $V_{S}=10 \mathrm{~V}$ for both male and female subjects with $R^{2}=0.9861,0.9959$ and $R^{2}=0.9841,0.9983$ respectively. Furthermore, the best fit models are also statistically significant with $p<0.001$ and $p<0.005$. It is worth noting that some other mathematical models also showed good results with close proximity in $R^{2}$, however, in comparison with that models, aforementioned models showed slightly better results and were more simple. With optimal initial trigger voltage ( $V_{S O}$ ) of $10 \mathrm{~V}$, the $V_{S M}$ could be accurately estimated in the very next triggering attempt. It was very close to the value obtained at $V_{S}=15 \mathrm{~V}$.

Due to high $R^{2}$ and in order to avoid tingling sensation to the subject, $V_{S}=10 \mathrm{~V}$ was selected for initial stimulation voltage.

\section{C. $\boldsymbol{\mu C}$ based auto-controlled biofeedback stimulator}

Table 4 outlines the proposed algorithm for $\mu C$ based measurement of $V_{L}$ as a faithful representation of skin resistance, relate $V_{L}$ to estimate $V_{L, S M}$ using Eq. (8) or Eq. (10), estimate $V_{S M}$ using Eq. (9) or Eq. (11) and finally generate the $V_{S M}$ via $\mathrm{BC}$ for automatic generation of supramaximal voltage for online measurements. The experimentation consists of two stages- offline and online stages as outlined in Table 4 . Finally, the $\mu C$ based auto-controlled simulator was designed, which is employed in the custom made NCS setup as shown in Fig. 9. The variations of $V_{S M}$ with DC of pulse train for both $1 \mathrm{kHz}$ and $10 \mathrm{kHz}$ are shown in Fig. 10. The linearity of $V_{S M}$ with DC is more prominent at $10 \mathrm{kHz}$ than at $1 \mathrm{kHz}$. Furthermore, the dynamic responses of the conventional stimulator and buck converter (section (e) of Fig. 5) of auto-controlled stimulator are depicted in Fig. 11. The rise and fall time of both responses were found to be $1 \mathrm{~ms}$. The ripple factors that measures the rms component contains in conventional stimulating pulse and BC output during the on-time were found to be 0.274 and 0.36 respectively. To exemplify the generation of pulse train in the $\mu C$ and corresponding $V_{S M}$ in the BC, the digital storage oscilloscope (DSO) display is shown in Fig. 12.

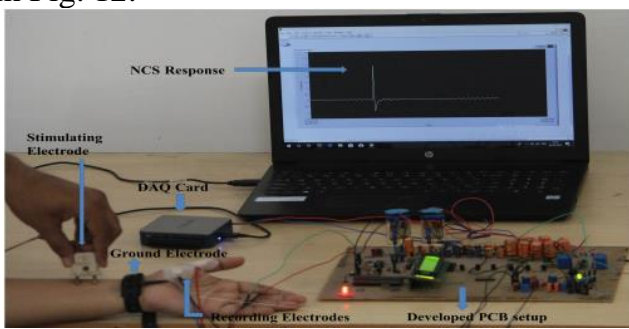

Fig. 9: Custom made NCS experimental setup with proposed $\mu C$-based auto-controlled stimulator.

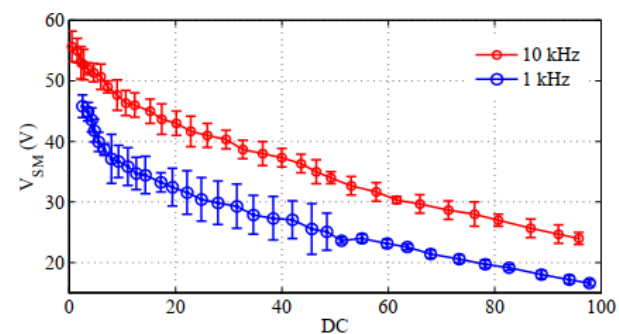

Fig. 10: The variation of $V_{S M}$ with DC with a pulse train of frequency $10 \mathrm{kHz}$ and $1 \mathrm{kHz}$ generated by $\mu C$.

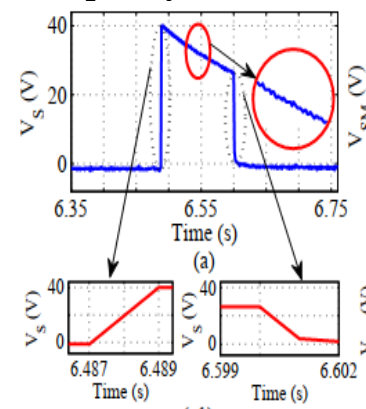

(a1)

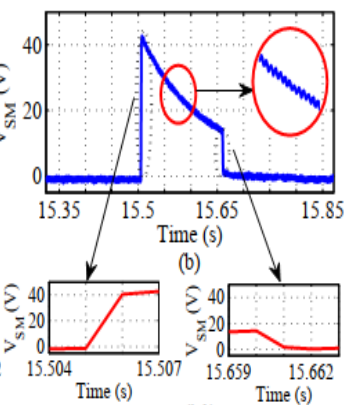

(b1)
Fig. 11: Dynamic responses of stimulating pulse (a) conventional stimulator (b) buck converter. (a1) and (b1) are rise (left) and fall (right) time responses of (a) and (b) respectively.

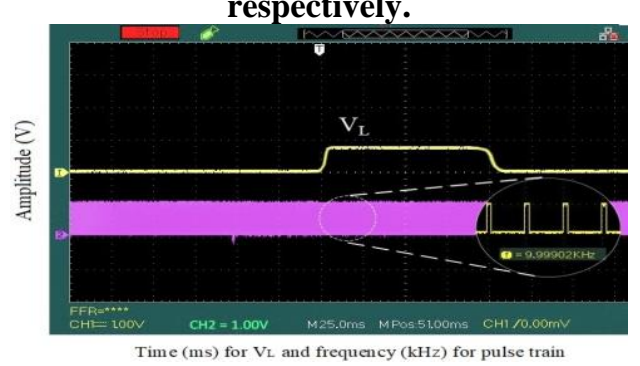

(a)

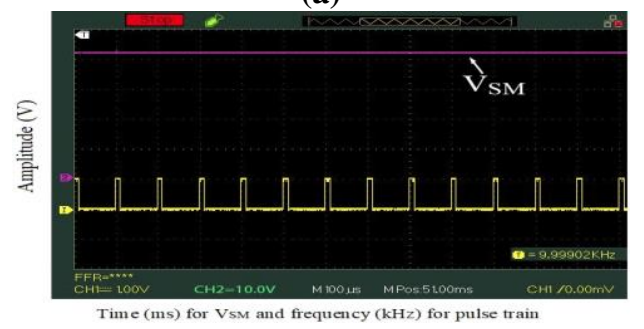

(b)

Fig. 12: DSO readings (a) $V_{L}$ and corresponding pulse train generated by the $\mu C$ which was applied to the $\mathrm{BC}$, (b) $V_{S M}$ of the BC with applied pulse train from the $\boldsymbol{\mu} C$ for a male subject of weight $65 \mathrm{~kg}$. Note that the zoomed portion in Fig. 12 (a)

indicates the pulse train of $10 \mathrm{kHz}$ frequency with a specific duty cycle.

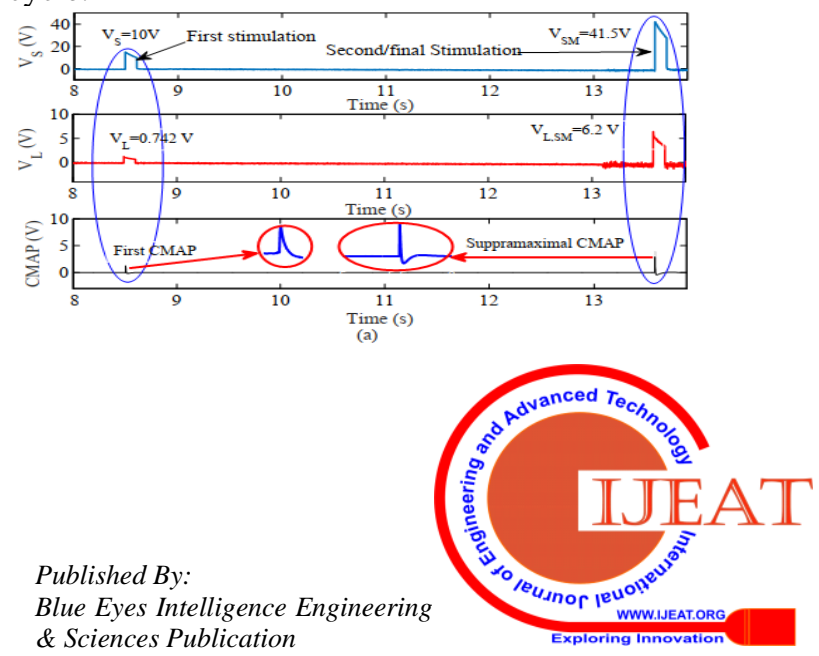




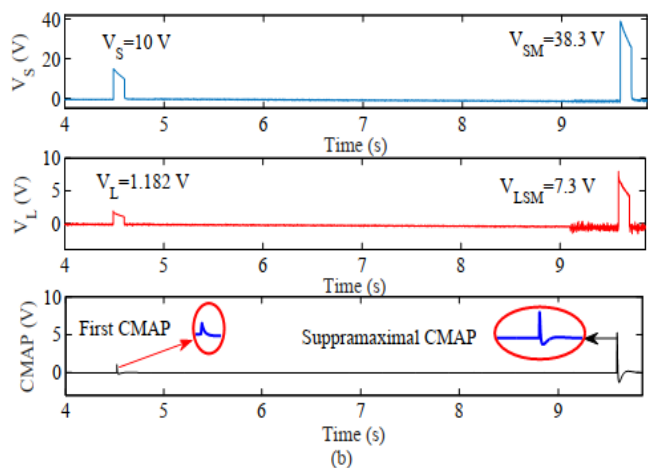

Fig. 13: Online measured signals for (a) male (age: 26 years, weight: $63 \mathrm{~kg}$ ) and (b) female (age: 25 years, weight: $61 \mathrm{~kg})$. Both subjects were excluded from the modeling data.

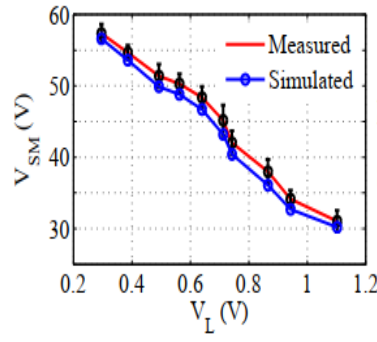

(a)

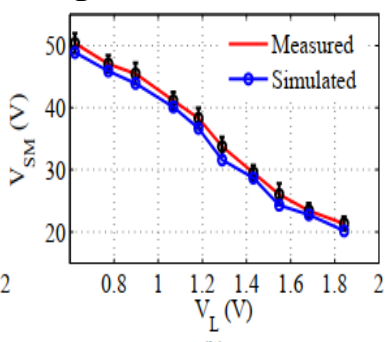

(b)
Fig. 14: Experimental values of $V_{S M}$ vs. $V_{L}$ for various subjects including males in (a) and females in (b)

The experiment was carried out on the proposed $\mu C$ based system for 20 new subjects (10 males and 10 females) which were not used in the modeling. The readings of $V_{L}$ for a male subject of $65 \mathrm{~kg}$ weight and subsequently obtained $V_{S M}$ at the BC output are shown in Fig. 12. Furthermore, $V_{L}$ and
CMAP at initial stimulating voltage $V_{S}=10 \mathrm{~V}$ and $V_{S M}=$ 41.5 V (male) and 38.3 V (female) are depicted in Fig. 13. As is evident, the optimal CMAP, i.e., supramaximal response as indicated by circle in Fig. 13 (a) at final stimulation is far superior to that of initial stimulation for both the participants. For new subjects, the responses for second/final stimulations were found as supramaximal responses which were verified by a neurophysiologist. The online experiment was performed over new participants and mean results of $V_{S M}$ for different $V_{L}$ over five repeated measurements are shown in Fig. 14 with repeatability $\sim 90 \backslash \%$. It is seen that high $V_{L}$ (i.e., low skin resistance) requires lower value of $V_{S M}$ for final stimulation to achieve the supramaximal responses. Quantitative difference of $V_{S M}$ between theoretical and experimental are $1.8 \backslash \%$ (for male) and $2.12 \backslash \%$ (for female) respectively, which evinces considerable improvement of the new method compared to methods described in section 1 . The investigation and analysis thus reveal that the proposed auto-controlled stimulator accurately generates the $V_{S M}$ for subjects not included in modeling. Our system provides supramaximal stimulus for proper NCS incorporating the skin-resistance as a comprehensive biofeedback parameter. This allows the proposed device to be used for stimulation of nerves in NCS/EMG applications without the need for repeated stimulation until supramaximal stimulus is obtained. Furthermore, Table 5 outlines many state-of-art methods presented in the section 1 with our method in terms of salient parameters, which also indicates the efficacy of our design.

Table 5: Outlines of characteristics and limitations of various reported studies

\begin{tabular}{|c|c|c|c|}
\hline Design system [] & Biofeedback parameter & Characteristics/Limitations & Applications \\
\hline 64-channel neurostimulator [1] & No & Deep brain stimulation & neurological disorders \\
\hline Programable neurostimulator [2] & No & $\begin{array}{l}\text { Generate rectangular pulse }(0-2.5 \\
\text { V).Model validated with rat only }\end{array}$ & Stimulation for rat \\
\hline Current stimulator [8] & No & $\begin{array}{l}\text { Complex design. High supply } \\
\text { voltage (i.e., } 15 \mathrm{~V} \text { ) }\end{array}$ & neurological disorders \\
\hline $\begin{array}{l}\text { CMOS-based neurostimulator } \\
\text { [9] }\end{array}$ & No & Complex design & Seizure detection \\
\hline Constant current-WNS [11] & No & $\begin{array}{l}\text { 100-channel design. Use biphasic } \\
\text { constant current. Programmable } \\
\text { system }\end{array}$ & motor fibers/muscle study \\
\hline VLSI based stimulation [12] & No & Constant current source & visceral nerves study \\
\hline $\begin{array}{l}\text { Biofeedback therapy system } \\
\text { [14] }\end{array}$ & $\begin{array}{l}\text { Fatigue parameter based on } \\
\text { sEMG }\end{array}$ & $\begin{array}{l}\text { High processing steps } \\
\text { Validation with limited datasets }\end{array}$ & nerve/muscle diagnosis \\
\hline EMG-biofeedback system [15] & $\begin{array}{l}\text { zero-crossings and turns /second } \\
\text { of EMG signal }\end{array}$ & $\begin{array}{l}\text { Limited features. Use of EMG } \\
\text { responses. }\end{array}$ & Muscle/fatigue analysis \\
\hline Biofeedback System [16] & $\begin{array}{l}\text { Signal features. } \\
\text { (EMG and galvanic skin } \\
\text { response) }\end{array}$ & lack of stimulator design & diagnostic application \\
\hline $\begin{array}{l}\text { Proposed biofeedback } \\
\text { stimulator }\end{array}$ & Skin-resistance & Voltage controlled stimulator & $\begin{array}{l}\text { Peripheral nerve analysis } \\
\text { Low power system (i.e., } 9 \text { V. Portable } \\
\text { and adaptable }\end{array}$ \\
\hline
\end{tabular}

\section{CONCLUSION}

This study addresses the measurement of human skin-resistance and proposed a $\mu C$-based programmed biofeedback stimulator using skin-resistance as a representative marker to generate supramaximal stimulation in order to avoid repeated trials. First, a custom made NCS setup was designed to collect physiological data for theoretical modeling and for finding optimal statistical models using the regression $R^{2}$ analysis. Then, an algorithm was then developed and embedded in a $\mu C$ for automatic generation of supramaximal stimulus voltage for online measurement. The programmed $\mu C$ triggers the specific pulse train of duty cycle corresponding to the optimal voltage of the programmed $\mu C$. This pulse train was applied to the $\mathrm{BC}$ that produced the final stimulating voltage. The system was tested using new participants with the custom made NCS setup using the proposed stimulator and results were demonstrated. Furthermore, close agreement of results 
between optimal voltage of the $\mu C$ and the output of the $\mathrm{BC}$ indicates the correctness of the biofeedback based stimulator design. The simulated and measured values are compared and show good agreement. Additionally, the proposed methodology was outlined in the context of many prior similar applications. Thus, this system is appropriate for stimulating nerves for getting NCS responses for real-time applications.

\section{ACKNOWLEDGEMENTS}

The authors would like to thank Dr. Mausumi Barthakur, Department of Neurophysiology, GNRC Hospital, Guwahati, India for the guidance and support to carry out the experiment and data collection as well as the volunteers of the department of Electronics and Communication Engineering, Tezpur University for helping in acquiring

NCS signals. Also, the authors would like to thank the Ministry of Micro, Small \& Medium Enterprises, India, for funding the project grant (No. 2(19)/2014/Inc).

\section{REFERENCES}

1. Lee, J., Rhew, H. G., Kipke D. R. et al.: “A 64 channel programmable closed-loop neurostimulator with 8 channel neural amplifier and logarithmic ADC" IEEE J. Solid-State Circuits, 2010,45(9), pp. 1935-1945.

2. Qian, X., Hao, H. W., Ma, B. Z. et al.: Programmable and implantable neurostimulator with novel stimulus waveforms for rat models, Electron. Lett., 2012, 48(17), pp. 1035-1036.

3. Dorgan, S. J., Reilly, R. B.: A model for human skin impedance during surface functional neuromuscular stimulation, IEEE Trans. Neural Syst. Rehabil. Eng., 1999, 7(3), pp. 341-348.

4. Taji, B., Chan, DC. A., Shirmohammadi, S.: Effect of Pressure on Skin-Electrode Impedance in Wearable Biomedical Measurement Devices, IEEE Trans. Instrum. Meas., 2018, 67, pp. 1900-1912.

5. Peckham, P. H., Knutson, J. S.: Functional electrical stimulation for neuromuscular applications, Annu. Rev. Biomed. Eng., 2005, 7, pp. 327-360

6. Mishra, U.K., Kalita, J.: Clinical Neurophysiology, 3rd ed., 2014, Elsevier Health Sciences Unit printing press, India.

7. Yang, B., Dong, Y.: A Portable Dual-Parameter Tester for Assessing Electrical Properties of Human Skin Surface, IEEE Sensors J.,

8. 2016, 16(2), pp. 426-435.

9. Charthad, J., Chang, T.C., Liu. Z. et al.: "A mm-Sized Wireless Implantable Device for Electrical Stimulation of Peripheral Nerves", IEEE Trans. Biomed. Circuits Syst., 2018, 12(2), pp. 257-270.

10. Kassiri, H., Bagheri, A., Soltani, N. et al.: "Battery-less tri-bandradio neuro-monitor and responsive neurostimulator for diagnostics and treatment of neurological disorders", IEEE J. Solid-State Circuits, 2016, 51(5), pp. 1274-1289.

11. Liu, X., Demosthenous,A., Donaldson,N. “An integrated implantable stimulator that is fail-safe without off-chip blocking-capacitors", IEEE Trans. Biomed. Circuits Syst.,2008,2(3), pp. 231-244.

12. Thurgood, B.K., Warren, D.J., Ledbetter, N.M. et al.: "A wireless integrated circuit for 100-channel charge-balanced neural stimulation", IEEE Trans. Biomed. Circuits Syst., 2009, 3(6) pp.405-414.

13. Greenwald, E., Wang, Q., Thakor, N.V.: "VLSI circuits for bidirectional interface to peripheral and visceral nerves", in proc. IEEE conf. Engineering in Medicine and Biology Society, Italy, 2015, pp. 2163-2166.

14. Pichorim, S.F., Vollmann, W., Pellanda, U.V. et al.: "Nerve Conduction Velocity Measurement: A didactic example", In Congreso Argentino de Bioingeniaria, Berlin,Germany 2009.

15. Zeng, D., Hu, Y., He, Q. "et al.: "Study of intelligent bio-feedback therapy system based on transcutaneous electrical nerve stimulation and surface EMG signals", in proc. IEEE conf. Information and Automation, China, 2013, pp. 374-378.

16. Im, J.J., Rho, D.H., Jeon, Y.J. et al.: "Extraction of parameters from EMG signals for the biofeedback electrical stimulation", in proc. IEEE conf. Engineering in Medicine and Biology, USA, 2002, pp. 133-134.

17. Jing, J., Zhang,W., Wang, Y. "et al.: "An intelligent biofeedback system based on pattern recognition and electroacupuncture imitating traditional Chinese medical acupuncture", in proc. IEEE conf. Intelligent Control and Automation, China, 2006, pp. 9454-9458.

18. Hazarika, A., Barman, P., Talukdar, C. et al.: "Real time implementation of a multi-domain feature fusion model using inherently available large sensor data", IEEE Trans. Industrial Informatics, 2019, 15 (12), pp.6231-6239.

19. Junior, P.O., Aguiar, P.R., Foschini, C.R. et al.: "Feature extraction using frequency spectrum and time domain analysis of vibration signals to monitoring advanced ceramic in grinding process", IET Sci. Meas. Technol., 2018, 13 (1), pp. 1-8.

20. Siuly, S., Alcin, O.F., Bajaj, V. et al.: "Exploring Hermite transformation in brain signal analysis for the detection of epileptic seizure”, IET Sci. Meas. Technol., 2018, 13 (1), pp. 35-41.

21. Al Ghayab, H.R., Li, Y., Siuly, S., et al.: "Epileptic EEG signal classification using optimum allocation based power spectral density estimation", IET Signal Process., 2018, 12 (6), pp. 738-747.

22. A, Lay-Ekuakille., G, Griffo Vergallo. et al.: "Implantable neurorecording sensing system: Wireless transmission of measurements", IEEE Sensors J., 2015, 15 (5), pp.2603-2613.

23. Arteaga-Falconi,J. S., Osman, H. Al and Saddik, A. El. "ECG authentication for mobile devices", IEEE Trans. Instrum. Meas. 2016, 65 (3), pp. 591-600.

24. Fraser, G. D., Chan, A. D. C. et al.: "Automated biosignal quality analysis for electromyography using a one-class support vector machine”, IEEE Trans. Instrum. Meas., 2014, 63 (12), pp. 2919-2930.

25. Damhorst, G. L., Watkins, N. N. et al.: "Micro- and Nanotechnology for HIV/AIDS Diagnostics in Resource-Limited Settings", IEEE Trans. Biomed. Eng, 2013, 60 (3), pp. 715-726.

26. Chi, Y. M., Jung, T. P., Cauwenberghs, G.: "Dry-contact and noncontact biopotential electrodes: Methodological review", IEEE Rev. Biomed. Eng., 2010, 3, pp. 106-119.

27. De Talhouet, T., Webster, J. R.: "The origin of skin-stretch-caused motion artifacts under electrodes", Physiol. Meas., 1996, 17, pp. 81-93.

28. Luna, J. L. V., Krenn, M., Ramarez, J. A. C. et al.: "Dynamic Impedance Model of the Skin-Electrode Interface for Transcutaneous Electrical Stimulation", PloS one, 2015, 10(6), pp. 1-15.

29. Talukdar, C,. Barman, R., Das Nilotpal et al., "Analysis of noise and its removal in nerve conduction study signal", Proc. IEEE int. conf. innovations in Electronics, Signal Proces. and Commun., India, 2017, pp. $143-148$.

30. Meweet, D. T. et al.: "Removing power line noise from recorded EMG", Engineering in Medicine and Biology Society., 2001, vol 3, pp. 2190-2193.

31. Gosselin, B., Ayoub, A. E., Roy, J. F. et al.: "A mixed-signal multichip neural recording interface with bandwidth reduction", IEEE Trans. Biomed. Circuits Syst., 2009, 3(3), pp. 129-141.

32. Hazarika, A., Dutta, L., Barthakur, M. et al.: "A Multiview Discriminant Feature Fusion-Based Nonlinear Process Assessment and Diagnosis Application to Medical Diagnosis", IEEE Instrum. Meas., 2018 99, pp. 1-9.

33. Koo, Y. S., Cho, C. S., Kim, B. J.: "Pitfalls in using electrophysiological studies to diagnose neuromuscular disorders", Clin. Neurosci., 2012, 8(1), pp.1-14.

34. Talukdar, C., Hazarika, A., Singh, A., et al.: "Voltage Controlled Stimulator for Nerve Conduction Study", Proc. IEEE int. conf. innovations in Electronics, Signal Proces. and Commun., India, 2019, pp. 13-17.

35. Chizmadzhev, Y. A., Zarnitsin, V. G., Weaver, J. C. et al.: "Mechanism of electroinduced ionic species transport through a multicellular lipid system", Biophys. J., 1995, 68(3), pp. 749-765

36. Grimnes, S: "Skin impedance and electro-osmosis in the human Epidermis", Med. Biol. Eng. Comput., 1983, 21(6), pp.739-749.

37. Ivorra, A.: Tissue electroporation as a bioelectric phenomenon: Basic concepts", in proc. Springer conf. Irreversible electroporation, Berlin, 2010, pp. 23-61.

38. Prokhorov, E. F., Gonzalez-Hernaandez, J., Vorobiev, Y. V. et al.: "In vivo electrical characteristics of human skin, including at biological active points", Med. Biol. Eng. Comput., 2000, 38(5), pp. 507-511.

39. Hlubik, J., Lhotska, L., Hlubik, P. et al.: "Changes in bioimpedance and body composition parameters depending on measurement conditions", Hygeia, 2013, 48(2), pp. 181-184.

40. Gitter, A. et al.: "Electrodiagnostic Instrumentation", American Association of neuromuscular and Electrodiagnostic Medicine, 2001.

41. Rosell, X., "Javier, J., Colominas, R.P. et al.: Skin impedance from $1 \mathrm{~Hz}$ to $1 \mathrm{MHz}$, IEEE Trans. Biomed. Eng., 1988, 35(8), pp. 649-651. 


\section{AUTHORS PROFILE}

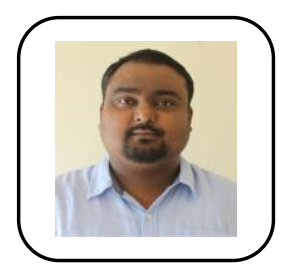

Champak Talukdar received the M.Sc. degree in Instrumentation from Gauhati University, Guwahati, Assam, India, in 2009 and M. Tech degree in Bioelectronics from Tezpur University, Tezpur, India, in 2011. He is currently working towards the Ph.D. degree in biomedical instrumentation and signal processing. His research interests include Nerve Conduction Study, machine learning, biomedical instrumentation, gas sensors and biomedical signal processing. Email: ctdon123@gmail.com.

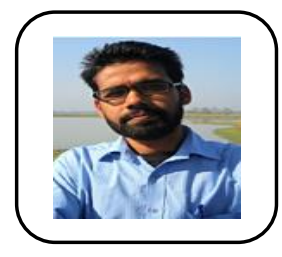

Anil Hazarika received the M.Sc. degree in Physics and the $\mathrm{M}$ Tech degree in Bioelectronics in 2009 and 2011 from Tezpur University, Tezpur, India respectively. He received the Ph.D. degree from Tezpur University, Tezpur, India in 2019. His research interests include mathematical modeling, biomedical signal processing, statistical signal processing, fuzzy logic, artificial neural network and its application in medical research. Email: anilhazarika8@gmail.com.

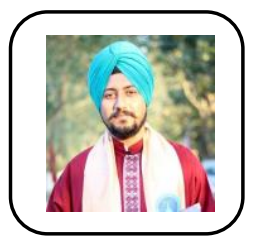

Amarprit Singh received the B.E degree in Power Electronics and Instrumentation Engineering 2013 from Dibrugarh University, India and and the $\mathrm{M}$ Tech degree in Bioelectronics in 2018 from Tezpur University, Tezpur, India. He is currently working towards the Ph.D. degree in Hand written tools in Bio sensing. His research interests include Nerve Conduction Study and Biosensors. Email: singhamarprit21@gmail.com.

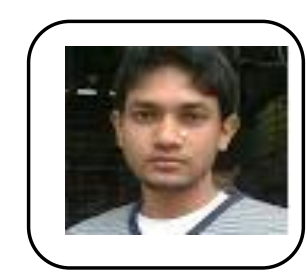

Nilotpal Das received the B.E degree in Power Electronics and Instrumentation Engineering 2014 from Dibrugarh University, India and and the $\mathrm{M}$ Tech degree in Bioelectronics in 2016 from Tezpur University, Tezpur, India. His research interests include Nerve Conduction Study and biomedical instrumentation.

Email: nilotpalofficial@gmail.com.

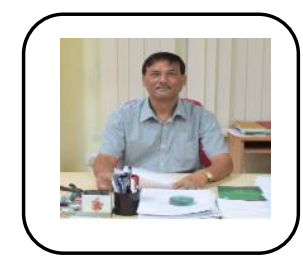

Manabendra Bhuyan received the Ph.D. degree from Gauhati University, Guwahati, India in 1999. He is currently a Professor with the Department of Electronics and Communication Engineering, Tezpur University, Tezpur, India. His research interests are biomedical signal processing, electronic instrumentation, machine olfaction,

and machine vision. He is the author of many books and research articles. Two patents are against his name. Prof. Bhuyan is a life member of Biosensor Society of India, CFTIR, Mysore, India.

Email: manab@tezu.ernet.in. 